\title{
Methicillin-resistant Staphylococcus aureus infection in Riveira (Galicia-North West of Spain). Impact of a nursing home MRSA control program on hospital admissions
}

José Antonio Díaz-Peromingo ${ }^{1 *}$, Marina Iglesias-Gallego², Emilio Padín-Paz², Jesús Grandes-lbáñez³, Joaquín Sánchez-Leira1, Florinda García-Suárez², Sonia Molinos-Castro², Paula Pesqueira-Fontán², Juan Saborido-Froján ${ }^{4}$, Javier Naveiro-Soneira² and M Carmen Gayol-Fernández ${ }^{2}$

*Correspondence: jose.antonio.diaz.peromingo@sergas.es

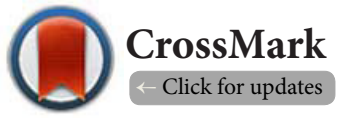

'Department of Internal Medicine, University Hospital Complex of Santiago, Santiago de Compostela (A Coruña), Spain.

2Department of Internal Medicine, Hospital da Barbanza, Riviera (A Coruña), Spain.

${ }^{3}$ Department of Internal Medicine, University Hospital Complex of Vigo, Vigo (Pontevedra), Spain.

${ }^{4}$ Department of Internal Medicine, Complex University Hospital of A Coruña, (A Coruña), Spain.

\begin{abstract}
Background: Methicillin-resistant Staphylococcus aureus (MRSA) is a very important multidrug-resistant pathogen with increase morbidity, mortality and related medical costs. MRSA infection has been described not also in hospitals but in long term care facilities such as nursing homes. MRSA strains can spread from hospitals to nursing homes and vice versa. Our objective is to study the incidence of MRSA infection in a community hospital, the prevalence of MRSA carriers in a nursing home and the impact of a program to control MRSA carriers at the nursing home on MRSA related hospital admissions.

Material and methods: The study has three parts. First part includes a retrospective study conducted to investigate patients hospitalized because of MRSA infection from 1998 to 2005. A nursing home was opened in 2002. In 2006, a cohort study among residents and caregivers at the nursing home to assess the prevalence of MRSA carriage was performed. When nasal culture was positive, intranasal mupirocin was administered. The retrospective part of the study and the intervention procedure at the nursing home were carried out simultaneously. The third part of the study was prospective. It was performed from 2006 to 2009 to evaluate the occurrence of new MRSA related hospital admissions. The study was finished in 2009.

Results: 74 patients were hospitalized because of MRSA related infections, mostly old men. MRSA was isolated from the sputum, blood and skin. The incidence of MRSA infection ranged from 3.03/100000 (2000, 2007, 2008) to 30.30/100000 habitants (2005). Eighteen patients $(24.32 \%)$ died during hospitalization. A total of 104 residents undergo nasal culture. MRSA was isolated in 9 (8.65\%). Among caregivers, 54 were examined. MRSA was present in 2 (3.70\%).

Conclusions: Following the opening of the hospital there was a progressive increase in MRSA infections with a peak in 2005. Mortality rate was near to $25 \%$ during hospitalization in MRSA infected patients. After the opening of the nursing home there was an increase in the incidence that dropped dramatically after performing the intervention study at the nursing home. Elderly, the high rate of MRSA carriers, the probable previous admission to hospital, including ICU stay of some patients, point to the need of eradicating MRSA carriers in order to reduce hospital infections. Nursing homes seem to be a suitable place to perform MRSA eradication.
\end{abstract}

Keywords: MRSA infection, MRSA spread, nursing home, elderly, caregiver

\section{Introduction}

Methicillin-resistant Staphylococcus aureus (MRSA) is the most common multidrug-resistant pathogen causing nosocomial infections in Europe [1]. Clinical manifestations of nosocomial infections caused by MRSA include urinary tract infection, lower respiratory tract infection (including pneumonia), gastrointestinal infection and skin infection. It has been estimated that there are approximately 170000 MRSA infections in European Healthcare systems each year with more than 5000 related deaths and costs of $€ 380,000,000$ per year [1]. This fact is associated with significant morbidity, increase in mortality rates, longer hospital stays, and higher medical costs [2-4].
The incidence of MRSA infection is increasing. New patterns of spread are emerging. In this sense, outbreaks of MRSA infections have been described not also in hospitals but in long term care facilities such as rehabilitation centres, nursing homes, military barracks, or correctional facilities. Hospital-acquired MRSA strains can spread outside the health care system because MRSA carriage is prolonged after hospital discharge. Risk factors for MRSA infection includes recent hospitalization, residence in a long-term care facility, surgical procedure, dialysis, indwelling vascular catheter, intravenous drug use, chronic skin lesions, worse Karnofsky score, and exposure to broad-spectrum antibiotics [5]. 
Nursing homes may have large reservoirs of MRSA, affecting residents and staff. This fact can result in persistent MRSA carriage $[6,7]$. Prevalence of MRSA carriage up to $50 \%$ in nursing homes residents has been reported, sometimes surpassing that found in intensive care units (7-24\%) or general hospital wards (6-12\%) [8-10]. At the same time, the increased prevalence of MRSA in healthcare settings, especially nursing homes, poses an increased risk of exposure to MRSA among healthcare workers (HCWs) $[11,12]$. In this population prevalence rates between 1 and 15\% have been reported [12].

Colonized residents or staff may spread MRSA in the environment via air or hands [6]. The anterior nares are presumed to be the primary reservoir for Staphylococcus aureus but it has been isolated also in extra-nasal locations such as oropharynx, rectum and axilla [13]. Asymptomatic colonization is often unrecognized. It generally precedes the development of MRSA infection playing a major role in the dissemination of MRSA between and within healthcare facilities. In this sense, MRSA colonization increases the risk of subsequent MRSA infection by 4 -fold to 13 -fold [14].

In addition, MRSA outbreaks in nursing homes are becoming more frequently associated with old buildings, insufficient isolation procedures, less strict MRSA policy, failed eradication attempts, staff working part time at several institutions at the same time and lack of formal healthcare education [6].

Among nursing home staff, MRSA prevalence rates between $1 \%$ and $15 \%$ have been reported $[\mathbf{6}, \mathbf{1 1}, \mathbf{1 5}]$. One limitation of these rates is the fact that these studies were carried out during outbreaks and not represent prevalence data in an endemic MRSA setting [11].

The following study was undertaken in response to local concerns that the incidence of community-associated MRSA was rising, especially after the opening of a nursing home facility in the same area resulting in a possible increase in hospital admissions related to MRSA infection. The study was performed in Riveira (Galicia, North West of Spain). There is no generalized and well established policy program regulating interventional procedures to assess MRSA carriages in nursing homes in Spain as well as other European countries [16] Nevertheless, there are some programs dealing with this issue when MRSA is detected at hospital [17]. Decolonization regimens in MRSA carriers usually include antibiotics like mupirocin, fusidic acid or a combination of them with chorhexidine. We choose a multiday regimen of intranasal mupirocin because of high efficacy and extended use $[18,19]$. Our aim is to study the prevalence of MRSA carriers in a nursing home, the incidence of MRSA infection in a community hospital, the impact of the opening of a nursing home in terms of hospital admissions and the implementation of a program to control MRSA carriers at the nursing home.

\section{Material and methods \\ Setting and study population}

The study was performed at Hospital da Barbanza, an 82 bed, community centre that provides medical assistance for a population of 66.000 inhabitants. This hospital is situated in Riveira (Galicia, North West of Spain). The hospital lacks an intensive care unit (ICU). Patients admitted because of MRSA related conditions were included from November 1998 (hospital opening) to October 2009. A nursing home was opened in Riveira (April 2002). We analyzed the possible impact of this opening in terms of hospital admissions due to MRSA infections and the prevalence of MRSA carriers in residents and staff at the nursing home. The study is divided in three parts. First we performed a retrospective study of MRSA related admissions to hospital between 1998 and 2005. Second, a cohort study was performed along May 2006 consisting of an intervention procedure within the nursing home facility. Study parts first and second were done simultaneously. The intervention consisted of bilateral nasal swabs of nursing home residents and nursing home staff to know the prevalence of MRSA carriers. Samples were enriched in a salt broth (7.5\%) with Polymyxin B $10 \mathrm{mg} / \mathrm{l}$ and then inoculated on mannitol salt agar for $S$. aureus and on Oxacillin screenplate $(6 \mathrm{mg} / \mathrm{l})$ for MRSA isolation. Strains with minimum inhibitory concentration (MIC) of $4 \mu \mathrm{g} / \mathrm{mL}$ or greater were considered to be resistant [20]. A MRSA carrier was defined as any nursing home resident or staff with a positive culture. The third part of the study was prospective reporting new MRSA related hospital admissions between 2006 and 2009 when the study was finished.

\section{Decolonization regimen}

We administered $2 \%$ mupirocin ointment application (twice daily for 7 days) when nasal culture was positive. New nasal culture 15 days later to assess eradication was performed. Variables like age, sex, associated diseases and mortality were also reported.

\section{Statistical analysis}

A descriptive analysis was performed using the SPSS package version 17.0. SPSS Inc. Chicago, IL, USA.

\section{Ethical considerations}

The study was approved by the local ethical committee and institutional review board (Comité Autonómico de Ética da Investigación Clínica-CAEIC-de Galicia).

\section{Results \\ Hospital MRSA related admissions}

A total of 74 patients were admitted to the Department of Internal Medicine suffering MRSA related infections in the whole study period. These infections were lower respiratory tract infections (excluding pneumonia) 34 cases, pneumonia 17 cases, urinary tract infection 13 cases, and subcutaneous cellular tissue infections 10 cases. Median age was 71 (range 43-91) years old; 51 (68.91\%) patients were men and 23 (31.09\%) women. MRSA was isolated from bloodstream in 14 cases, from skin in 9 cases and from sputum in 51 cases. 
Distribution of MRSA infection related admissions during the study period is shown in Figure 1. The annual incidence of MRSA infection ranged from 3.03/100000 (years 2000, 2007 and 2008) to 30.30/100000 habitants (year 2005). Eighteen patients (24.32\%) died during hospitalization from a MRSA related condition.

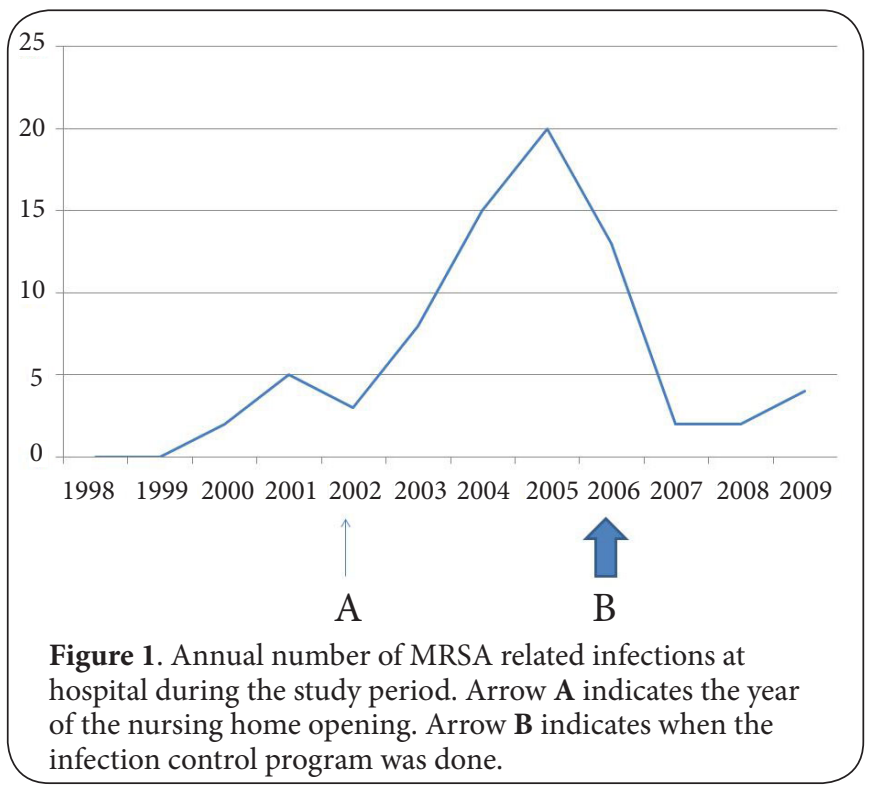

\section{Nursing home intervention}

A total of 104 residents undergo nasal culture ( $98 \%$ of the total). Median age was 73 (range 56-89) years old; 49 (47.11\%) were men and 55 (52.89\%) women. Nasal culture was positive in $42(40.38 \%)$ cases. The most frequent isolated bacteria were Staphylococcus aureus non-methicillin resistant $(28 ; 26.92 \%)$, MRSA $(9 ; 8.65 \%)$ and Pseudomonas aeruginosa $(2 ; 1.92 \%)$. The most common associated diseases were chronic obstructive pulmonary disease (COPD) (40 patients), hypertension (22 patients), anaemia (16 patients), hyperlipidemia (15 patients) and smoking, heart failure and atrial fibrillation (each one with 12 patients). On the other hand, $54 \mathrm{HCWs}$ undergo nasal culture (95\% of the total). Median age was 31 (range 23-54) years old. Among them, 6 (11.11\%) were men and 48 (88.89\%) women. Nasal culture was positive in $17(31.48 \%)$ cases. The most frequent isolated bacteria were Staphylococcus aureus non-methicillin resistant $(14 ; 25.92 \%)$ and MRSA $(2 ; 3.70 \%)$. All residents and staff with positive culture were treated and nasal eradication was reached in all of them except two residents who remained positive after mupirocin therapy.

\section{Discussion}

A total of 74 patients were admitted to the department of Internal Medicine because of MRSA related infections. They were mainly men and elderly patients. The most important site of infection was the respiratory tract. Following the opening of the hospital there was a progressive increase in
MRSA infections with a peak in 2005 (maximum incidence $30.30 / 100000$ habitants). Mortality rate was near to $25 \%$ during hospitalization in MRSA infected patients. Following the opening of the nursing home there was an increase in the incidence that drops dramatically after performing the intervention program. The most frequent underlying conditions were COPD, hypertension and anaemia.

Haley et al., reported an $8.7 \%$ prevalence of MRSA colonization in hospitalized patients focussing on the importance of an active surveillance of MRSA carriers [2]. In this sense, patients with only MRSA colonization, excluding those with clinical MRSA infection, can be significant sources for the spread of MRSA in a hospital $[2,11]$.

At present, it is not clear whether hospitals should identify MRSA colonization at the time of admission or not. By one hand, patients admitted with either MRSA infection or colonization can transmit MRSA to other patients at hospital. On the other hand, comprehensive admission culturing is expensive. Rationale of admission nose culture should be based on the clinical probability of being infected or colonized by MRSA.

Furuno et al., detected $76 \%$ of admission MRSA while requiring surveillance cultures for $65 \%$ of admissions in patients who had been hospitalized in the past year [21]. When other items like history of nursing home stay in the past year, MRSA infection ever, homelessness, jail stay, promiscuity, and illicit drug use were included, admission MRSA was detected in $83 \%$ cases with a surveillance culturing burden of $53 \%$ of admissions [2].

Elderly patients are now healthier and are operated upon, or treated on acute and high-risk units like intensive care units (ICUs) than previously [22]. Additionally, the presence of associated comorbidities is a marker of vulnerability in the elderly [8]. Patients with major health problems are increasingly discharged to home health care or nursing home facilities, creating new opportunities for the transmission of hospital acquired MRSA [23]. Some of these patients become MRSA carriers in the hospital and are discharged to a nursing home. They can spread MRSA to other nursing home residents that could be admitted to hospital weeks or months later carrying MRSA and spreading it at hospital [24]. This situation contains several battlefronts. Hypothetically, MRSA surveillance culturing could be performed the time of hospital of nursing home admission. In our study, almost $10 \%$ of the nursing home residents were colonized by MRSA. These patients have chronic related diseases that commonly need hospitalization. In these patients, hospitalization could help to spread MRSA in the hospital setting affecting other patients and hospital workers.

Some reports have shown that MRSA has spread from the hospital environment to other healthcare institutions such as nursing homes using molecular epidemiology analysis. These other health care institutions become important reservoirs for MRSA transmission [24]. Patients could be infected at hospital, discharged to a nursing home and infect other residents that 
could be admitted to the hospital weeks, months or years after. Figure 2 shows a model of MRSA dissemination between hospitals and the community (including nursing homes).

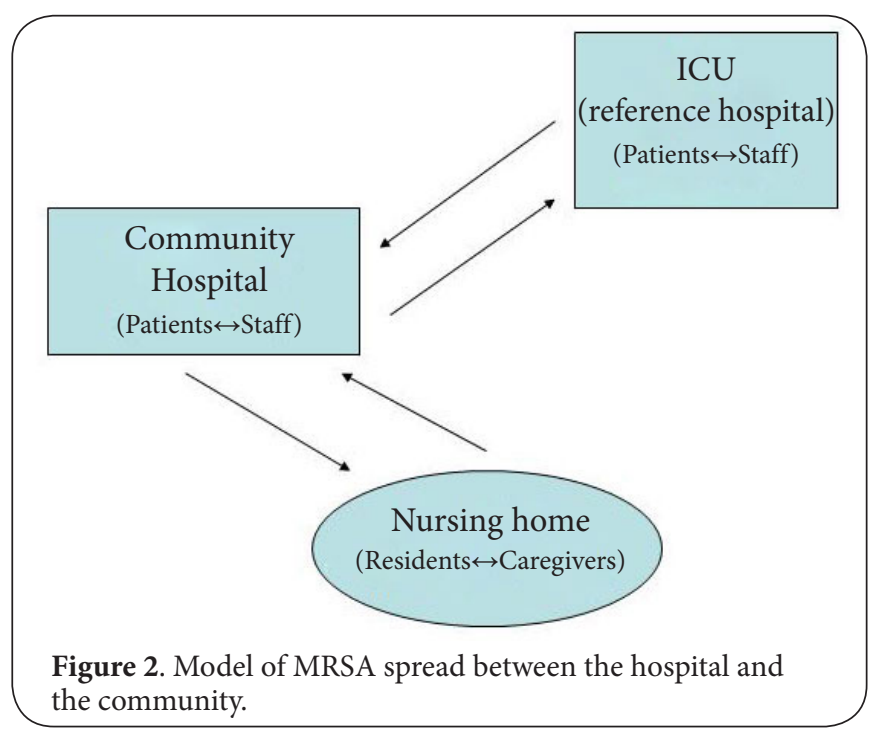

MRSA transmission in nursing homes occurs because of poor hand hygiene both in residents and care workers or deficient environmental cleaning. In this sense, a strict screening and decolonization of colonized individuals at admission should be very important. Additionally, improving hand hygiene and environmental cleaning would be useful [25].

In our study, there is a high rate of nursing home residents with positive nasal culture $(40.38 \%)$ cases. The most frequent isolated bacteria were Staphylococcus aureus non-methicillin resistant (26.92\%). MRSA prevalence was $8.65 \%$. Due to this fact, assessment of MRSA colonization in every new resident and probably caregivers should be done to detect carriers and perform decolonization. MRSA carrying status should be assessed when a hospitalized patient is discharged to a nursing home.

The increased prevalence of MRSA in healthcare settings poses an increased risk of exposure to MRSA among caregivers [12]. We reported a positive nasal culture in $17(31.48 \%)$ cases among caregivers. The most frequent isolated bacteria was also Staphylococcus aureus non-methicillin resistant (25.92\%). MRSA prevalence was $3.70 \%$.

The importance of recognizing MRSA colonization among caregivers remains in the fact that MRSA infection can cause severe health problems among this population and may lead to long-term incapacity [11]. It has been reported that up to half of the staff in nursing homes worry of acquiring MRSA infection [6].

Risk factors for MRSA carriage in caregivers are recent hospitalization of residents and cross-infection through staff caring for more dependent residents [26]. Both MRSA prevalence in residents and care workers in our study are clearly lower than other reported by Baldwin et al., In this study the prevalence of MRSA carriers among residents was $23.3 \%$ and $7.5 \%$ in HCWs [27].

The opening of a nursing home in the area explains, at least in part, the increasing rate in hospital MRSA related admissions in the following years. As we could see after decontaminating MRSA carriers among residents and caregivers, MRSA related infections at hospital dropped dramatically in the following years.

Several possible tasks to decrease dissemination of MRSA in nursing homes include strict screening and decolonization of colonized individuals at admission, decolonization of colonized residents and hand hygiene improve of both residents and caregivers [25]. In our study, decolonization of both residents and health workers lead to a diminution in MRSA related hospital admissions by $35 \%$ in the year of the intervention in the nursing home (2006) and by $84.7 \%$ in 2007 , pointing to a very high efficacy of this measure.

This study has several limitations. Prevalence rates were based upon nasal swabs and not sampling of multiple body sites. Additionally, we do not know if the patients were previously admitted to an ICU in other hospital becoming infected in that setting. As a result, MRSA prevalence reported might be underestimated. Finally, we do not assess the incidence of MRSA related hospital admissions due to community MRSA other than nursing home.

Elderly, the high rate of MRSA carriers and the possible previous admission to other hospital, including ICU stay, point to the need of eradicating these carriers in order to reduce the rate of further hospital infections due to MRSA. Probably, the nursing home is a suitable and easiest place to do this.

\section{Competing interests}

The authors declare that they have no competing interests.

\section{Authors' contributions}

\begin{tabular}{|l|l|l|l|l|l|l|l|l|l|l|l|}
\hline $\begin{array}{l}\text { Authors' } \\
\text { contributions }\end{array}$ & JD & MI & EP & JG & JS & FG & SM & PP & JS & JN & MG \\
\hline $\begin{array}{l}\text { Research concept } \\
\text { and design }\end{array}$ & $\checkmark$ & $\checkmark$ & $\checkmark$ & $\checkmark$ & $\checkmark$ & $\checkmark$ & $\checkmark$ & $\checkmark$ & $\checkmark$ & $\checkmark$ & $\checkmark$ \\
\hline $\begin{array}{l}\text { Collection and/or } \\
\text { assembly of data }\end{array}$ & $\checkmark$ & $\checkmark$ & $\checkmark$ & -- & -- & -- & $\checkmark$ & -- & -- & -- & -- \\
\hline $\begin{array}{l}\text { Data analysis and } \\
\text { interpretation }\end{array}$ & $\checkmark$ & -- & -- & $\checkmark$ & $\checkmark$ & $\checkmark$ & $\checkmark$ & $\checkmark$ & -- & $\checkmark$ & - \\
\hline Writing the article & $\checkmark$ & -- & -- & -- & $\checkmark$ & -- & -- & -- & $\checkmark$ & -- & $\checkmark$ \\
\hline $\begin{array}{l}\text { Critical revision of } \\
\text { the article }\end{array}$ & $\checkmark$ & -- & -- & $\checkmark$ & -- & $\checkmark$ & $\checkmark$ & -- & -- & $\checkmark$ & $\checkmark$ \\
\hline $\begin{array}{l}\text { Final approval of } \\
\text { article }\end{array}$ & $\checkmark$ & $\checkmark$ & $\checkmark$ & $\checkmark$ & $\checkmark$ & $\checkmark$ & $\checkmark$ & $\checkmark$ & $\checkmark$ & $\checkmark$ & $\checkmark$ \\
\hline Statistical analysis & $\checkmark$ & -- & -- & $\checkmark$ & $\checkmark$ & $\checkmark$ & -- & -- & $\checkmark$ & -- & $\checkmark$ \\
\hline
\end{tabular}

Publication history

Editors: Tobias Alecio Mattei, Ohio State University, USA. Ahmad Amro, Al Quds University, Abu Dies, Palestine.

EIC: Istiaq Quadri, King Abdul Aziz University, Jeddah, Saudi Arabia. Received: 21-Jan-2014 Final Revised: 21-Mar-2014

Accepted: 27-Mar-2014 Published: 15-Apr-2014 
Diaz-Peromingo et al. Research Journal of Infectious Diseases 2014, http://www.hoajonline.com/journals/pdf/2052-5958-2-1.pdf

\section{References}

1. Kock R, Mellmann A, Schaumburg F, Friedrich AW, Kipp F and Becker $K$. The epidemiology of methicillin-resistant Staphylococcus aureus (MRSA) in Germany. Dtsch Arzteb/ Int. 2011; 108:761-7. | Article | PubMed Abstract | PubMed Full Text

2. Haley CC, Mittal D, Laviolette A, Jannapureddy S, Parvez N and Haley RW. Methicillin-resistant Staphylococcus aureus infection or colonization present at hospital admission: multivariable risk factor screening to increase efficiency of surveillance culturing. J Clin Microbiol. 2007; 45:3031-8. | Article | PubMed Abstract | PubMed Full Text

3. Engemann JJ, Carmeli Y, Cosgrove SE, Fowler VG, Bronstein MZ, Trivette SL, Briggs JP, Sexton DJ and Kaye KS. Adverse clinical and economic outcomes attributable to methicillin resistance among patients with Staphylococcus aureus surgical site infection. Clin Infect Dis. 2003; 36:592-8. | Article | PubMed

4. McHugh CG and Riley LW. Risk factors and costs associated with methicillin-resistant Staphylococcus aureus bloodstream infections. Infect Control Hosp Epidemiol. 2004; 25:425-30. I Article I PubMed

5. Lucet JC, Paoletti X, Demontpion C, Degrave M, Vanjak D, Vincent C, Andremont A, Jarlier V, Mentre F and Nicolas-Chanoine $\mathrm{MH}$. Carriage of methicillin-resistant Staphylococcus aureus in home care settings: prevalence, duration, and transmission to household members. Arch Intern Med. 2009; 169:1372-8. I Article I PubMed

6. Thorstad M, Sie I and Andersen BM. MRSA: A Challenge to Norwegian Nursing Home Personnel. Interdiscip Perspect Infect Dis. 2011; 2011:197683. | Article | PubMed Abstract | PubMed Full Text

7. Denis O, Jans B, Deplano A, Nonhoff C, De Ryck R, Suetens C and Struelens MJ. Epidemiology of methicillin-resistant Staphylococcus aureus (MRSA) among residents of nursing homes in Belgium. J Antimicrob Chemother. 2009; 64:1299-306. I Article I PubMed

8. Murphy CR, Quan V, Kim D, Peterson E, Whealon M, Tan G, Evans K, Meyers H, Cheung M, Lee BY, Mukamel DB and Huang SS. Nursing home characteristics associated with methicillin-resistant Staphylococcus aureus (MRSA) Burden and Transmission. BMC Infect Dis. 2012; 12:269. | Article | PubMed Abstract | PubMed Full Text

9. Bradley SF, Terpenning MS, Ramsey MA, Zarins LT, Jorgensen KA, Sottile WS, Schaberg DR and Kauffman CA. Methicillin-resistant Staphylococcus aureus: colonization and infection in a long-term care facility. Ann Intern Med. 1991; 115:417-22. I Article I PubMed

10. Furuno JP, Hebden JN, Standiford HC, Perencevich EN, Miller RR, Moore AC, Strauss SM and Harris AD. Prevalence of methicillin-resistant Staphylococcus aureus and Acinetobacter baumannii in a long-term acute care facility. Am J Infect Control. 2008; 36:468-71. | Article | PubMed Abstract | PubMed Full Text

11. Haamann F, Dulon M and Nienhaus A. MRSA as an occupational disease: a case series. Int Arch Occup Environ Health. 2011; 84:259-66. | Article | PubMed Abstract | PubMed Full Text

12. Albrich WC and Harbarth S. Health-care workers: source, vector, or victim of MRSA? Lancet Infect Dis. 2008; 8:289-301. I Article I PubMed

13. Mertz D, Frei R, Jaussi B, Tietz A, Stebler C, Fluckiger $U$ and Widmer AF. Throat swabs are necessary to reliably detect carriers of Staphylococcus aureus. Clin Infect Dis. 2007; 45:475-7. | Article I PubMed

14. Bowler WA, Bresnahan J, Bradfish A and Fernandez C. An integrated approach to methicillin-resistant Staphylococcus aureus control in a rural, regional-referral healthcare setting. Infect Control Hosp Epidemiol. 2010; 31:269-75. I Article I PubMed

15. Davis KA, Stewart JJ, Crouch HK, Florez CE and Hospenthal DR. Methicillin-resistant Staphylococcus aureus (MRSA) nares colonization at hospital admission and its effect on subsequent MRSA infection. Clin Infect Dis. 2004; 39:776-82. I Article I PubMed

16. Latour K, Catry B, Broex E, Vankerckhoven V, Muller A, Stroobants R, Goossens $\mathrm{H}$ and Jans $\mathrm{B}$. Indications for antimicrobial prescribing in European nursing homes: results from a point prevalence survey. Pharmacoepidemiol Drug Saf. 2012; 21:937-44. | Article I PubMed

17. Protocolo de actuación ante pacientes infectados/colonizados por Staphylococcus aureus resistente a meticilina (SARM). 2014.
18. Robicsek A, Beaumont JL, Thomson RB, Jr., Govindarajan G and Peterson LR. Topical therapy for methicillin-resistant Staphylococcus aureus colonization: impact on infection risk. Infect Control Hosp Epidemiol. 2009; 30:623-32. I Article I PubMed

19. Huang SS, Septimus E, Kleinman K, Moody J, Hickok J, Avery TR, Lankiewicz J, Gombosev A, Terpstra L, Hartford F, Hayden MK, Jernigan JA, Weinstein RA, Fraser VJ, Haffenreffer K, Cui E, Kaganov RE, Lolans $K$, Perlin JB and Platt R. Targeted versus universal decolonization to prevent ICU infection. N Engl J Med. 2013; 368:2255-65. | Article | PubMed

20. Swenson, J.M., J.B. Patel and J.H. Jorgensen. Special phenotypic methods for detecting antibacterial resistance. In: Murray, P. R., E. J. Baron, J.H. Jorgensen, M. L. Landry, and M.A. Pfaller (ed.). Manual of clinical microbiology, 9th ed. American Society for Microbiology, Washington, D.C. USA. 2007.

21. Furuno JP, McGregor JC, Harris AD, Johnson JA, Johnson JK, Langenberg $P$, Venezia RA, Finkelstein J, Smith DL, Strauss SM and Perencevich EN. Identifying groups at high risk for carriage of antibiotic-resistant bacteria. Arch Intern Med. 2006; 166:580-5. | Article | PubMed

22. Fukuta $Y$, Cunningham CA, Harris PL, Wagener MM and Muder RR. Identifying the risk factors for hospital-acquired methicillin-resistant Staphylococcus aureus (MRSA) infection among patients colonized with MRSA on admission. Infect Control Hosp Epidemiol. 2012; 33:1219-25. I Article I PubMed

23. Rozenbaum R, Silva-Carvalho MC, Souza RR, Melo MC, Gobbi CN, Coelho LR, Ferreira RL, Ferreira-Carvalho BT, Schuenck AL, Neves FM, Silva LR and Figueiredo AM. Molecular characterization of methicillin-resistant Staphylococcus aureus disseminated in a home care system. Infect Control Hosp Epidemiol. 2006; 27:1041-50. I Article I PubMed

24. Pfingsten-Wurzburg S, Pieper DH, Bautsch W and Probst-Kepper $M$. Prevalence and molecular epidemiology of meticillin-resistant Staphylococcus aureus in nursing home residents in northern Germany. J Hosp Infect. 2011; 78:108-12. I Article I PubMed

25. Chamchod F and Ruan S. Modeling the spread of methicillin-resistant Staphylococcus aureus in nursing homes for elderly. PLoS One. 2012; 7:e29757. I Article I PubMed Abstract I PubMed Full Text

26. Lasseter G, Charlett A, Lewis D, Donald I, Howell-Jones R and McNulty CA. Staphylococcus aureus carriage in care homes: identification of risk factors, including the role of dementia. Epidemiol Infect. 2010; 138:68696. | Article | PubMed

27. Baldwin NS, Gilpin DF, Hughes CM, Kearney MP, Gardiner DA, Cardwell $C$ and Tunney MM. Prevalence of methicillin-resistant Staphylococcus aureus colonization in residents and staff in nursing homes in Northern Ireland. J Am Geriatr Soc. 2009; 57:620-6. I Article I PubMed

\section{Citation:}

Díaz-Peromingo JA, Iglesias-Gallego M, Padín-Paz E, Grandes-Ibáñez J, Sánchez-Leira J, García-Suárez F, Molinos-Castro S, Pesqueira-Fontán P, SaboridoFroján J, Naveiro-Soneira J and Gayol-Fernández MC. Methicillin-resistant Staphylococcus aureus infection in Riveira (Galicia-North West of Spain). Impact of a nursing home MRSA control program on hospital admissions. Res J Infect Dis. 2014; 2:1. http://dx.doi.org/10.7243/2052-5958-2-1 